Copyright (C) 2021 University of Bucharest Printed in Romania. All rights reserved

ISSN print: $1224-5984$

ISSN online: $2248-3942$

\title{
Ex situ preservation in medium-term culture of the threathened taxon Dianthus nardiformis Janka
}

\author{
IRINA HOLOBIUC ${ }^{\mathbf{1}}$, RODICA CATANĂ ${ }^{\mathbf{1}}$, FLORENT,A HELEPCIUC ${ }^{\mathbf{1}}$, \\ CARMEN MAXIMILIAN ${ }^{1}$, MONICA MITOI ${ }^{1}$, GINA COGĂLNICEANU ${ }^{1}$
}

${ }^{1}$ Institute of Biology, Romanian Academy, Bucharest, Romania

\begin{abstract}
Our aim was to elaborate an efficient and reproducible protocol for medium-term culture of the threatened taxon Dianthus nardiformis. To reduce the growth, sucrose, mannitol, polyethylene glycol, Abscisic acid and Jasmonic acid were tested. For assessing the in vitro response, the growth and regeneration were registered after different time intervals.

Mannitol is the most effective for medium-term preservation viable cultures which can be maintained unlimited time through transfer at every 3 months. In its presence, somatic embryogenesis was induced and in vitro growth in the minimal cultures was reduced between 9 and 12 times comparing to the control.

Antioxidant enzymes assay revealed qualitative and quantitative differences among the experimental variants, and also between different concentrations of the same compound in correlation with the growth reduction and regeneration. POX was the most suitable to detect the efficiency of different treatments to induce medium-term cultures.
\end{abstract}

Keywords Medium-term, mannitol, somatic embryogenesis, antioxidant enzymes.

To cite this article: HOLOBIUC I, CATANĂ R, HELEPCIUC F, MAXIMILIAN C, MITOI M, COGĂLNICEANU G. Ex situ preservation in medium-term culture of the threathened taxon Dianthus nardiformis Janka. Rom Biotechnol Lett. 2021; 26(2): 2416-2422. DOI: $10.25083 / \mathrm{rbl} / 26.2 / 2416.2422$

$\triangle$ *Corresponding author: MONICA MITOI, Institute of Biology, Romanian Academy, 296 Spl Indepenţei St., zip code 060031, Bucharest, Romania, Tel.: 00402239072, Fax: 00402219071

E-mail: monica.carasan@ibiol.ro 


\section{Introduction}

Plant conservation became an important aim of the humankind, more than one third of plant species being rare, endangered, and threatened by extinction (RAJASEKHARAN \& SAHIJRAM, 2015) needing to be preserved both in situ and ex situ, with $20 \%$ available to be reintroduced into the wild.

Ex situ conservation based on biotechnology was developed to save wild threatened species (GONZÁLEZBENITO \& MARTÍN, 2011; KRISHNAN et al, 2011; MUÑOZ-CONCHA \& DAVEY 2011, PIJUT et al, 2011; CHAUHAN, 2016). Small amounts of tissues, organs or seeds can be collected without affecting the natural populations (PENCE, 2002). Among different ex situ approaches, medium-term preservation is an efficient and not expensive approach (CRUZ et al, 2013), involving growth limiting factors (physical or/and chemical) for reducing the growth to establish minimal or slow growth cultures (CHA-UM \& KIRDMANEE, 2007). Some medium-term conservation protocols were previously developed in other threatened Dianthus taxa as D. callizonus, D. tenuifolius, D. superbus L. ssp. speciosus (HOLOBIUC \& BLÎNDU 2006), D. spiculifolius, D. glacialis ssp. gelidus (HOLOBIUC et al, 2009b, 2010b), D. trifasciculatus (HOLOBIUC et al, 2014), D. ingoldbyi (ARDA et al, 2016),

Dianthus nardiformis Janka, a perennial plant, with pink flowers, is an endemic endangered vulnerable element from the South-East of Romania, Dobrogea region (DIHORU \& NEGREAN, 2009) and Bulgaria on the Black-Sea Coast and Danubian Plain (TZONEV 2004).

The aim of our study was to establish a medium-term culture protocol using growth limiting compounds for $e x$ situ preservation of this taxon. The effect of different factors was evaluated by measuring the growth and regeneration in correlation with the effect of oxidative stress effect on antioxidant enzymes.

\section{Material and Methods}

Plant material and culture conditions: double node stem fragment of about $10 \mathrm{~mm}$ detached from vitroplants (HOLOBIUC et al, 2009) were used as explants. Five inocula were cultured on a jar of $6 \mathrm{~cm}$ diameter $/ 10 \mathrm{~cm}$ high, with 5 jars/variant ( 25 replicates/variant). All the cultures were maintained in the growth chamber at 2000 lux $\left(27 \mu \mathrm{mol} / \mathrm{m}^{2} / \mathrm{s}\right)$, with $16 / 8$ photoperiod and $25^{\circ} \mathrm{C}$ temperature. The media variants tested to induced growth retardation were based on MS formula (MURASHIGE \& SKOOG, 1972), added with B5 vitamins mixture (GAMBORG, 1968), solidified with agar (Duchefa Plant Agar) $8 \mathrm{~g} / \mathrm{l}$ and $\mathrm{pH}$ adjusted at 5.8 before autoclavation. MS medium was supplemented with different compounds: M1-87,6 mM sucrose used as control, M2-87.6 mM sucrose $+164.7 \mathrm{mM}$ mannitol, M3-87.6 mM sucrose +329 mM mannitol, M4-175.2 mM sucrose, M5-262.9 mM sucrose, M6-87,6 $\mathrm{mM}$ sucrose + $60 \mathrm{mM}$ PEG 4000, M7-87.6 mM sucrose + $75 \mathrm{mM}$ Abscisic acid (ABA), M8-87.6 mM sucrose $+23 \mathrm{mM}$ Jasmonic acid (JA).
Slow-growth cultures evaluation: the response of the cultures in the limiting growth conditions was evaluated based on two parameters: (i) the maximum height (length) of the tallest regenerant/explant(mm) and (ii) the number of regenerants/explant, registered after 40, 80 and 120 days of culture. Depending on the experimental variant, were developed shoots, somatic embryos or remain as swollen meristems. The best developed regenerant height was measured after 40 and 80 days, because after these intervals some cultures degenerated (M5) or was grown needing the transfer on larger vessels (M1, M8), the others maintained reduced.The recorded values are expressed as average values \pm SD for 25 replicates/experimental variant. The results were statistical analyzed using ANOVA and Tukey Multiple Comparison test with 95\% confidence intervals at P-values < 0.05) (SPSS software).

Light microscopy analyses on histological samples. Aggregates of somatic embryos developed on mannitol added variants were prepared as fallow: fixation in $3.7 \%$ formaldehyde, dehydration in $70^{\circ}, 85^{\circ}, 96^{\circ}$ ethyl alcohol series for 15 minutes, 3 times immersion in buthyl alcohol for 6 hours, finally, the immersion twice in benzene for 15 minutes and the inclusion in paraffin at $60^{\circ} \mathrm{C}$ during 2 hours. The pieces were sectioned at $7 \mu \mathrm{m}$ thickness using a LKB microtome. For paraffin removal, the slides were immersed in xylene for 30 minutes, then transferred in a $96^{\circ}-15^{\circ}$ alcohol series for 15 minutes, washing and staining in Hemalaun Mayer for 10 minutes, washing in running tap water. The samples were visualized in light microscopy at a DOCUVAL microscope.

Biochemical analyses. The peroxidases (POX), superoxide dismutases (SOD), catalases (CAT) activity and electrophoretic spectra were analyzed for cultures maintained on different media variants 120 days. The extraction was performed by grinding the plant tissue in $50 \mathrm{mM}$ Tris- $\mathrm{HCl}$ buffer $\mathrm{pH} 8$, added with $2 \mathrm{mM} \mathrm{Na} \mathrm{m}_{2}$ EDTA and $4 \%$ PVP. The homogenate was centrifuged at $15000 \mathrm{rpm}$ for $20 \mathrm{~min}$. The POX enzymatic activity was measured at $470 \mathrm{~nm}$ absorbance (GARCIA-LIMONES et al, 2002). Electrophoresis was carried out in non-denaturing PAGE system at $4^{\circ} \mathrm{C}$ in $10 \%$ polyacrylamide migration gel (respectively $8 \%$ for peroxidase and catalase). SOD detection was based on Beauchamp \& Fridovich, (1971) method. The CAT activity was assayed at $240 \mathrm{~nm}$ according to Garcia-Limones et al. (2002) method. In order to locate SOD isoformes, the gel was incubated in $36 \mathrm{mM}$ phosphate buffer pH 7.8 supplemented with $2.45 \mathrm{mM}$ NBT, $28 \mathrm{mM}$ TEMED and $2.8 \times 10^{-5} \mathrm{M}$ riboflavin. For detection of bands with $\mathrm{CAT}$ activity $0.003 \% \mathrm{H}_{2} \mathrm{O}_{2}$ in $0.01 \mathrm{M}$ phosphate buffer, $\mathrm{pH}$ 7. For POX analysis, the gel was incubated in $0.5 \mathrm{M}$ acetate buffer $\mathrm{pH} 5$ with $0.08 \%$ benzidine and $\mathrm{H}_{2} \mathrm{O}_{2}$.

\section{Results}

\section{Evaluation of medium-term cultures:}

On the control variant, the lateral shoots developed well and fast, several regenerants emerged from the lateral meristems and rooting occurred easily. In the case of PEG, mannitol at lower level and sucrose adition, despite the induced osmotic stress, lateral shoots developed from the first weeks (Fig. 1). 


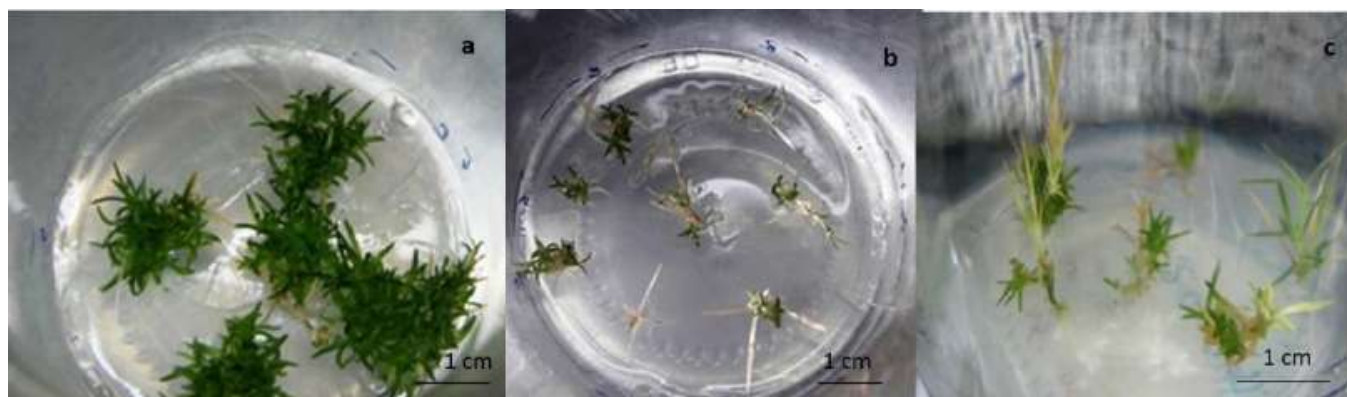

Figure 1. Aspects of medium-term cultures of D. nardiformis on MS medium added with: a) $60 \mathrm{mM}$ PEG; b) $329 \mathrm{mM}$ mannitol; c) $262.9 \mathrm{mM}$ sucrose after 40 days of culture.

After 40 days of culture, a decreasing of the tallest regenerant length on the variants supplemented with osmolytes as sucrose, mannitol and PEG (M2, M3, M4,
M5, M6)was recorded (Table 1). PEG addition determined a reduction of growth (Fig. 1a), but its effect was lower comparing to mannitol (Fig. 1 b).

Table 1. Evaluation of medium-term cultures of $D$. nardiformis. The values represent the average $\pm \mathrm{SD}$, the results with the same letter did not differ signifficantly

\begin{tabular}{|l|c|c|c|c|c|}
\hline \multirow{2}{*}{ Variant } & $\begin{array}{c}\text { Maximum regenerants length/ explant } \\
(\mathbf{m m})\end{array}$ & \multicolumn{3}{c|}{ The number of regenerants/ explants } \\
\cline { 2 - 6 } & $\mathbf{4 0}$ days & $\mathbf{8 0}$ days & 40 days & $\mathbf{8 0}$ days & 120 days \\
\hline M1 & $22.4 \pm 12.77 \mathrm{a}$ & $50.26 \pm 29.72 \mathrm{a}$ & $7.26 \pm 5.33 \mathrm{a}$ & $9.33 \pm 6.00 \mathrm{a}$ & $12.93 \pm 6.69 \mathrm{a}$ \\
\hline M2 & $2.4 \pm 0.50 \mathrm{~b}$ & $9.06 \pm 10.03 \mathrm{c}$ & $8.66 \pm 8.71 \mathrm{a}$ & $20.26 \pm 11.68 \mathrm{~b}$ & $52 \pm 19.99 \mathrm{~b}$ \\
\hline M3 & $1.8 \pm 0.51 \mathrm{~b}$ & $2.8 \pm 1.20 \mathrm{~b}$ & $2.6 \pm 0.82 \mathrm{~b} \mathrm{c}$ & $4.86 \pm 1.92 \mathrm{bc}$ & $22.26 \pm 18.92 \mathrm{c}$ \\
\hline M4 & $13.4 \pm 7.44 \mathrm{a}$ & $30.26 \pm 23.60 \mathrm{a}$ & $4.33 \pm 1.67 \mathrm{~b}$ & $10.73 \pm 4.96 \mathrm{a}$ & $18.73 \pm 12.13 \mathrm{a}$ \\
\hline M5 & $4.2 \pm 1.66 \mathrm{c}$ & $10.8 \pm 14.29 \mathrm{c}$ & $4.46 \pm 2.06 \mathrm{~b}$ & $12.06 \pm 7.46 \mathrm{a}$ & $13.26 \pm 9.89 \mathrm{a}$ \\
\hline M6 & $4.06 \pm 1.62 \mathrm{c}$ & $6.2 \pm 1.61 \mathrm{c}$ & $5.6 \pm 3.99 \mathrm{~b}$ & $18.2 \pm 6.96 \mathrm{~b}$ & $46.2 \pm 24.69 \mathrm{~b}$ \\
\hline M7 & $2.4 \pm 1.80 \mathrm{~b}$ & $3.46 \pm 3.46 \mathrm{~b}$ & $1.13 \pm 0.3 \mathrm{c}$ & $1.2 \pm 0.56 \mathrm{c}$ & $1.53 \pm 0.63 \mathrm{~d}$ \\
\hline M8 & $19.33 \pm 19.33 \mathrm{a}$ & $31.93 \pm 19.00 \mathrm{a}$ & $7.06 \pm 5.50 \mathrm{a}$ & $12.33 \pm 7.42 \mathrm{a}$ & $13.8 \pm 9.24 \mathrm{a}$ \\
\hline
\end{tabular}

Mannitol at $329 \mathrm{mM}$ level (M3) was the most limiting factor, with small buds emerging from the lateral meristems (Fig. 1b). In the variant M2, with lower mannitol level $(164.7 \mathrm{mM})$, the effect was not so strong, but the regenerants length was reduced comparing to the control. Presence of $175.2 \mathrm{mM}$ sucrose (M4) did not significantly reduce the growth of the shoots, but the higher level (262.9 mM-M5)had a more pronounced effect (Fig. 1c,
Table 1) similarly to PEG added variant (M6). ABA (75 mM in M7) inhibited the growth of the meristems, they remaining viable for 3-4 months, no rooting occurred. JA (23 mM-in M8 variant) did not affect the growth and the number of shoots. The extension of culture at 80 days, ensured the growth limitation in the case of mannitol, PEG and sucrose (Table 1). While roots did not develop in presence of PEG, it grown on mannitol media.

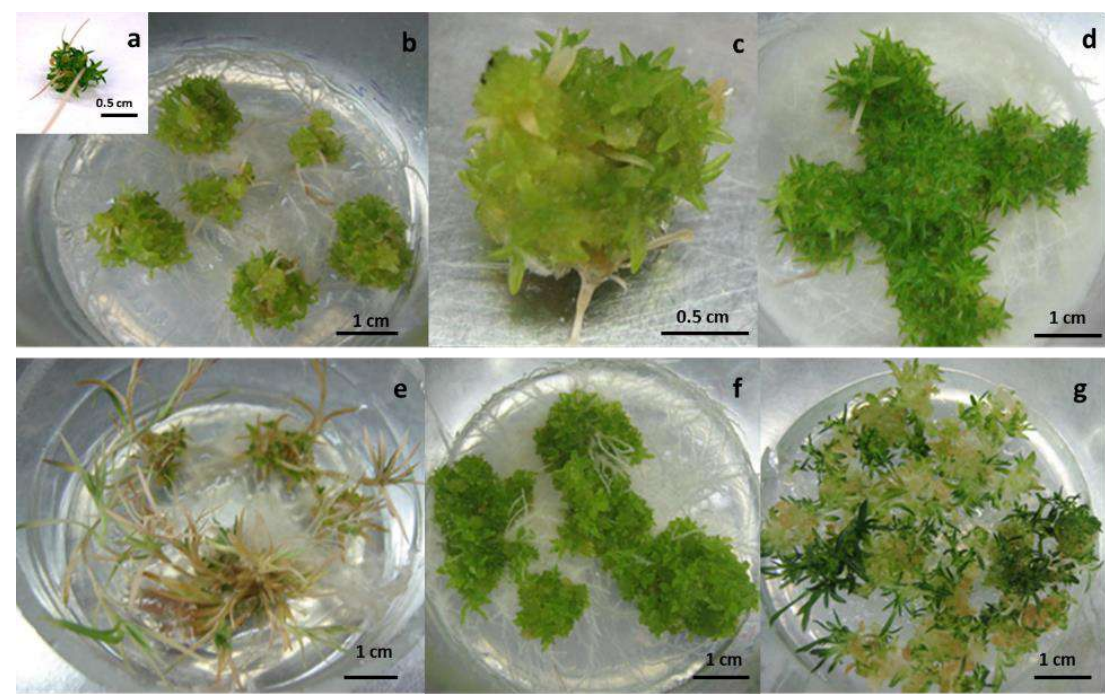

Figure 2. Aspects of medium-term cultures of $D$. nardiformis maintained on $164.7 \mathrm{mM}$ mannitoladded medium (M2): during 60 days (a), 80 days (b), detail of a highly regenerative aggregate at 80 days (c), 120 days (d) and respectively on medium added with $262.9 \mathrm{mM}$ sucrose (M5) 80 days (e), 329 mM mannitol (M3) during 120 days (f) and 60 mM PEG (M6) 160 days with vitrification (g). 
The regenerative structures after 40 days (Table 1) varied between 1.13 in presence of $\mathrm{ABA}$ and 8.66 on mannitol lower level. After 80 days, the best results of regeneration were recorded on $\mathrm{M} 2$ at $164.7 \mathrm{mM}$ mannitol (Fig. 2b, c) and M6 -medium with PEG (Fig. 2g, Table 1). Sucrose at high level determined the etiolation and death of already developed shoots, despite some new buds emerged, they degenerated over time (Fig. 2e). On the variant with JA (M8), the development is the same as in control, continued to grow and rooting occuread easily. After 120 days, despite the limited growth, the regeneration increased in the case of M2, M3, M6 variants (Table 1). Despite the good regeneration in presence of $\mathrm{PEG}$, vitrification was noticed.
In the case of M2 (with lower mannitol), in the first weeks were developed shoots, but subsequently, somatic embryogenesis (SE) occurred (Fig. 2a, b, c, d), while on M3, SE was induced from the first weeks with lower rate and than increased later (Fig. 2f). SE had the initial origin in the lateral meristems from the explants and underwent continuous and asynchronous (Fig. 3a, c, d), somatic embryos having apical and basal meristems being easily converted into plants (Fig. 3b). Histological analysis revealed different stages of $\mathrm{SE}$ and recurrent development of somatic embryos with no vascular connection with the origin tissue (Fig. 3c, d).

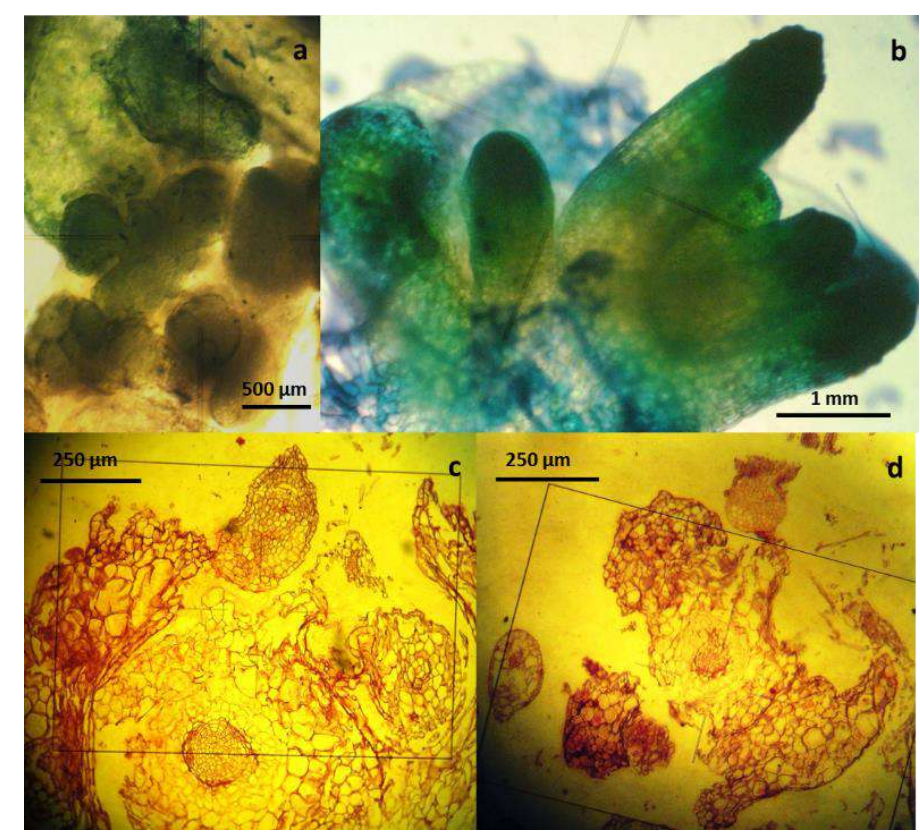

Figure 3. Aspects of direct somatic embryogenesis in $D$. nardiformis induced in the presence of mannitol after 120 days of culture in fresh samples: (a) Globular somatic embryos; (b) Developed plantlet originated in somatic embryos; (c, d). Histological sections of embryogenic aggregates - different stages of SE.

\section{Biochemical analysis in D. nardiformis medium- term cultures}

POX spectrum revealed qualitative and quantitative differences among the experimental variants, and also between different concentrations of the same compound (Fig. 4D), being correlated very well with the growth. In case of limited growth, the bands from the fast migration zone disappeared as in the case of the high level of mannitol (M3) 5, 6 and 7 isoforms or had a low expression for M5 variant with increased sucrose and for M6 with PEG. The POX activity is highly correlated with its spectrum, a decrease was detected in the case of high levels of osmolytes (M3, M5, M6) (Fig. 4A), while variants with moderate levels (M2, M4) had an increased activity. The SOD activity decreased in the case of higher levels of osmolytes as in M3 (329 mM mannitol), M5 (262.9 mM sucrose), M6 (60 mM PEG) being also corelated with the inhibition of the elongation process and growth (Fig. 4B). Regarding SOD spectrum, three isoforms were expressed in all variants, but one band was more intense on $329 \mathrm{mM}$ mannitol (M3) (Figure 4E).

In case of CAT, the electrophoresis revealed differences in enzyme banding pattern for mannitol and PEG variants (Fig. 4F). It can be noticed a slightly decrease of the CAT activity (Fig. 4C) on higher levels of mannitol and sucrose supplement variants.

\section{Discussions}

The survival and regeneration of in vitro culture is affected by chemical factors used to induce minimal cultures, imposing to establish the most suitable approach. While in vitro response and growth of $D$. nardiformis was good (HOLOBIUC et al, 2009a, 2010a), the reaction in resctricted growth conditions was different depending on compound and level applied: axillar shooting (PEG, sucrose, JA, mannitol at lower level), SE in the case of mannitol at higher concentration and after the prolonged exposure to lower level similar to other experiments in Dianthus related taxa (HOLOBIUC et al, 2009b, 2010b, 2014). 

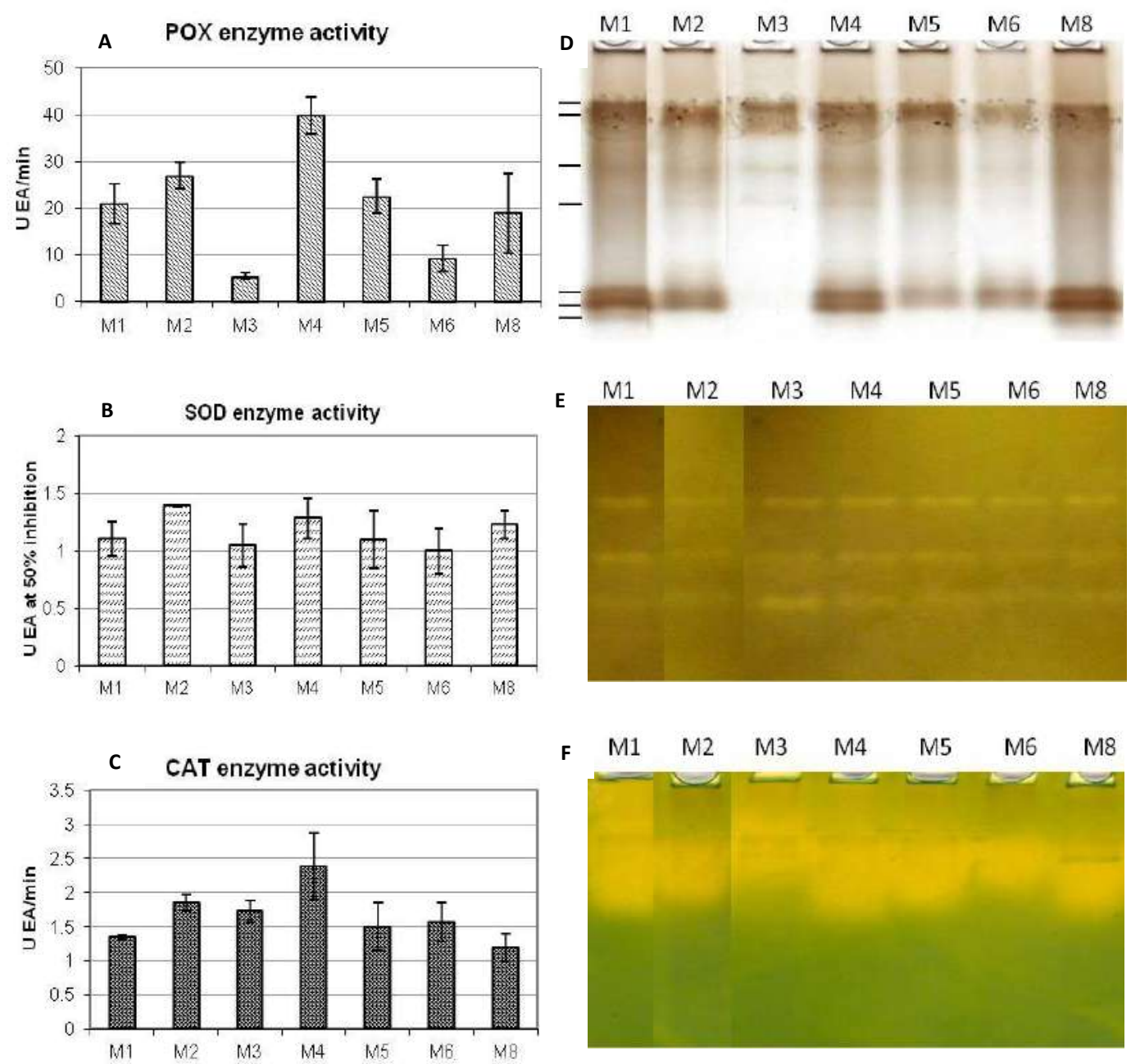

Figure 4. The activity of POX (A), SOD (B), CAT (C) and spectra of POX (D), SOD (E), CAT (F) in Dianthus nardiformis medium-term cultures after 120 days of culture.

Mannitol proved the most suitable to establish medium-term culture, while in case of PEG, despite the growth limitation and good regeneration, during the time, vitrification appeared. Sucrose reduced the growth and ensured the regeneration, but at the lower level its effect is no so pronounced, and at higher lever despite a limited growth, etiolation appeared because the stress. ABA did not allowed in vitro development at level tested, just keep alive lateral meristems of the explants for a limited period. ABA was reported to induced growth inhibition, improving the drought and salt resistance, besides its role in senescence (SHARP et al, 1994). JA in our experiment did not affect the growth and shoots formation which were as in control, despite it was reported to be a growth inhibitor (KIM et al, 2009). SE reported in D. nardiformis was similarly as in other Dianthus sp. (HOLOBIUC et al, 2009c) allowing a high regeneration, being a source propagules for conservative and practical aim. Direct SE from leaf with adition of growth regulators was reported in a cultivated Dianthus, PEG being necessary just for embryos maturation in short-term culture (YANTCHEVA et al, 1998). In our experiment, mannitol was a factor of growth limitation, but also a promotor of SE. The are evidences that embryogenic competence is activate by osmolytes (FEHER et al, 2003). Different stress factors was also reported to induce SE (ZAVATTIERI et al. 2010) as cold, heat, osmotic or nutrient stress probably because they stimulate the endogenous synthesis of $\mathrm{ABA}$ at a level which can trigger the somatic embryogenesis (KARAMI $\&$ SAIDI, 2008). In a related taxon $D$. ingolbyi, a reliable medium-term protocol at $4{ }^{\circ} \mathrm{C}$ with $58 \%$ survival rate was reported (ARDA et al, 2016), but mannitol was better tolerated, with a significant growth reduction between 9-12 times comparing to the control, correlated with 90$100 \%$ survival and with a high regeneration. Concerning biochemical evaluation, POX, SOD and CAT spectrum were correlated with variants tested as in a former study in Dianthus sp., antioxidant enzymes being susceptible to the nature, level, duration of exposure to osmolytes and by the capacity of the species to overcome the stress (MITOI et 
al, 2009). The three POX isoforms might be involved in cell elongation, exhibiting the highest polymorphism. These enzymes counteract ROS (hydroxyl anion and hydrogen peroxide) which can induce cell damages and even death if protective mechanism fails to detoxify (POLLE, 1995). On the other hand, mannitol can be accumulate in significant amounts, lowering cellular osmotic potential acting also as ROS scavenger (BOHNERT \& SHEVELEVA, 1998, RUIJTER et al, 2003). Absence of POX isoforms on higher mannitol may be due to mannitol ROS scavenger role. For SOD, the isoforms were expressed in all variants, also with one band more intense at higher mannitol variant. CAT spectrum revealed differences on mannitol and PEG variants where regeneration was higher. Lower level of osmolytes allowed to plants to overcome the oxidative stress through increasing the antioxidant enzymes activity, but at higher stress, the plants capacity to neutralize ROS declines, some phenotypical changes could appear(dwarfness, etiolation), the viability loss, death or activation of survival mechanisms (as SE). Similary, in D. trifasciculatus, biochemical analyses also shown that POX and CAT were sensitive to the different treatments, increased mannitol influenced the intensity of the bands even two months after its removal (HOLOBIUC et al, 2014).

\section{Conclusions}

The factors tested for minimal cultures had different effects on the limitation of the growth and development of regeneratives structures. Mannitol was the most efficiently to ensure a growth limitation of 9 to 12 times lower comparing to the control and to induce as a stress response, a high regeneration through SE generating hundred of propagules in small space and with reduced labor. Biochemical analysis after 120 days proved that antioxidant enzymes activity increased in a compensated system that tend to overcome the oxidative stress generated by different chemical factors while in the decompensated system, antioxidant enzymes activity was decreased, being not able to counteract the oxidative stress. POX was the most sensitive to detect the effect of factors used to limit in vitro growth. Isoenzymes patterns were in fact correlated to the adaptation to osmotic stress, growth reduction and regeneration process.

\section{Acknowledgements}

This study was funded by the projects "Biodiversity consolidation through ex situ preservation and somaclonal variability evaluation using molecular techniques in endemic or endangered taxa from Natura 2000 Romanian sites" (31-008/18.09.2007) and "Plant bioechnology for biodiversity conservation and durable development" RO1567-IBB06/2017.

\section{Conflict of Interest}

The authors have no conflict of interest to declare.

\section{References}

1. ARDA H, DAYAN S, KARTAL C, GÜLER N. In vitro conservation of critically endangered Dianthus ingoldbyi Turrill under slow growth conditions. Trakya University Journal of Natural Sciences. 2016; 17(1): 47-54.

2. BOHNERT HJ, SHEVELEVA E. Plant stress adaptations-making metabolism move. Curr Opin Plant Biol. 1998; 1:267-274.

3. BEAUCHAMP C. and FRIDOVICH I, 1971. Superoxide dismutase: improved assays and an assay applicable to acrylamide gels. Anal. Biochem. 1971; 44: 276-287.

4. CHAUHAN RS. Biotechnological approaches for conservation ofrare, endangered and threatened plants. Int Journal of Scientific and Research Publications. 2016; 6(12): 10-14.

5. CHA-UM S, KIRDMANEE C. Minimal Growth in vitro culture for preservation of plant species. Fruit, Vegetable and Cereal Science and Biotechnology. 2007; 1(1): 13-25.

6. CRUZ-CRUZ CA, GONZÁLEZ-ARNA OMT, ENGELMANN F. Biotechnology and conservation of plant biodiversity. Resources. 2013; 2: 73-95.

7. DIHORU GH, NEGREAN G. Cartea roșie a plantelor vasculare din România. Editura Academiei Române, București. 2009.

8. FEHER A, PASTERNAK TP, DUDITS D. Transition of somatic plant cells to an embryogenic state. Plant Cell Tissue Organ Cult. 2003; 74: 201-228.

9. GAMBORG OL, MILLER RA, OJIMA K. Nutrient requirements of suspension cultures of soybean root cells. Exp Cell Res. 1968; 50: 151-158.

10. GARCIA-LIMONES C, HERVÁS A, NAVASCORTÉS JA, JIMÉNEZ-DÍAZ RM, TENA M. Induction of an antioxidant enzyme system and other oxidative stress markers associated with compatible and incompatible interactions between chickpea (Cicer arietinum L.) and Fusarium oxysporum f. sp. ciceris. Physiol Mol Plant Pathol. 2002; 61(6): 325-337.

11. GONZÁLEZ-BENITO ME, MARTIN C. In Vitro preservation of spanish biodiversity. In Vitro Cell. Dev. Biol-Plant. 2011; doi:10.1007/s11627-010-9333-4.

12. HOLOBIUC I, BLÎNDU R. Improvement of the micropropagation and in vitro medium-term preservation of some rare Dianthus species, Contributii Botanice. 2006; 41(2): 143-151. 
13. HOLOBIUC I, BLÂNDU R, CRISTEA V. Researches concerning in vitro conservation of the rare plant species Dianthus nardiformis Janka. Biotechnol. \& Biotechnol. Eq. 2009 a; 23(2): 221-224.

14. HOLOBIUC M, BLÎNDU R, MITOI M, HELEPCIUC F, CRISTEA V. The establishment of an in vitro gene bank in Dianthus spiculifolius Schur. and D. glacialis ssp. gelidus (Schott Nym. et Kotschy). The initiation of a tissues collection and the characterization of the cultures in minimal growth conditions. Ann For Res. 2009 b; 52: 14-26.

15. HOLOBIUC I, BREZEANU A, BLINNDU R. Somatic embryogenesis induction in presence of moderate osmotic stress, synthetic seeds production in rare Dianthus species from Romanian Flora as a tool for ex situ conservation. Proc. of the $2^{\text {nd }}$ International Symposium" New Research in Biotechnology" Series F, Special Volume, 2009 Biotechnology, Bucharest, ISSN 1224-7774. 2009c: 69-77.

16. HOLOBIUC I, BLÎNDU R, CRISTEA V. Researches concerning in vitro cultures optimization of the vulnerable species Dianthus nardiformis Janka. Analele Universităţii din Oradea-Fascicula Biologie. 2010a; XVII (1): 116-121.

17. HOLOBIUC I, MITOI M, BLÎNDU R HELEPCIUC F. The establishment of an in vitro gene bank in Dianthus spiculifolius Schur. and D. glacialis ssp. gelidus (Schott Nym. et Kotschy) Tutin: II. Medium-term cultures characterization in minimal growth conditions. Rom. Biotechn. Lett. 2010 b 15 (2):5111-5119.

18. HOLOBIUC I, VOICHIŢĂ C, CATANĂ R, MITOI M, HELEPCIUC F. Medium-term preservation of Dianthus trifasciculatus kit ssp. parviflorus through minimal cultures. Muzeul Olteniei Craiova. Oltenia. Studii şi comunicări. Ştiinţele Naturii. 2014; 30(1): 57-66.

19. KARAMI O, SAIDI A. The molecular basis of stressinduced somatic embryogenesisres of Daucus carota. Plant Cell Rep. 2008; 20: 408-415. DOI 10.1007/ s11033-009-9764-3

20. KIM EH, KIM YS, PARK SH, KOO YJ, CHOI YD, CHUNG YY, LEE IJ, KIM JK. Methyl Jasmonate reduces grain yield by mediating stress signals to alter spikelet development in rice. Plant Physiolofy. 2009; 149: 1751-1760.

21. KRISHNAN P, DECRUSE S, RADHA R. Conservation of medicinal plants of Western Ghats, India and its sustainable utilization through in vitro technology. In Vitro Cell Dev-Pl. 2011; 47. 110-122. doi:10.1007/s11627-011-9344-9.
22. MITOI ME, HOLOBIUC I, BLÎNDU R. The effect of mannitol on antioxidative enzymes in vitro long term cultures of Dianthus tenuifolius and Dianthus spiculifolius, Romanian Journal of Biology - Plant Biology. 2009; 54(1): 25-33.

23. MUÑOZ-CONCHA D, DAVEY M. Micropropagation of the endangered Chilean tree, Gomortega keule. In Vitro Cell Dev- Pl. 2011; 47. 170-175. 10.1007/ s11627-010-9331-6.

24. PENCE V. Cryopreservation and in vitro methods for ex situ conservation of pteridophytes. Fern Gazette. 2002; 16: 362-368.

25. PIJUT PM, LAWSON SS, MICHLER CH. Biotechnological efforts for preserving and enhancing temperate hardwood tree biodiversity, health, and productivity. In Vitro Cell Dev-Pl. 2011; doi:10.1007/ s11627-010-9332-5

26. POLLE A. Mehler reaction- Friend or foe in photosynthesis. Bot Acta. 1995; 109: 84-94.

27. RAJASEKHARAN PE, SAHIJRAM L. In vitro conservation of plant germplasm. In: Bir Bahadur, Manchikatla Venkat RaJAm, Leela Sahijram, K.V. Krishnamurthy (Ed.): Plant Biology and Biotechnology (Vol II: Plant Genomics and Biotechnology). New York: Springer Verlag, 2015; pp. 417-443.

28. RUIJTER GJG, BAX M, PATEL H, FLITTER SJ, VAN DE VONDERVOORT PJI, RONALD P, DE VRIES R, VANKUYK PA, VISSER J. Mannitol is required for stress tolerance in Aspergillus niger conidiospores. Eukaryot Cell. 2003; 2(4): 690-698.

29. SHARP RE, WU Y, VOETBERG GS, SAAB I, LENOBLE ME. Confirmation that abscisic acid accumulation is required for maize primary root elongation at low water potentials. J of Exp Bot. 1994; 45: 1743-1751.

30. TZONEV R. New data and summarized information on the chorology of some rare, threatened and endemic plants in the midle Danube plain and Balkan foothill region. Ann. Univ. Sofia "St. Kl. Ohridski” Fac. Biol. 2 - botany. 2004; 97: 59-70.

31. YANTCHEVA A, VLAHOVA M, ANTANASSOV A. Direct somatic embryogenesis and plant regeneration of carnation (Dianthus caryophyllus L.). Plant Cell Rep. 1998; 18: 148-155.

32. ZAVATTIERI MA, FREDERICO AM, LIMA M, RUI $\mathrm{S}$, ARNHOLDT-SCHMITT B. Induction of somatic embryogenesis as an example of stress-related plant reactions. Electron J Biotechn. 2010; 13(1): 1-9. 